Disponível em:

http://editora.unoesc.edu.br/index.php/race

RACE, Joaçaba, v. 17, n. 1, p. 29-54, jan./abr. 2018

\title{
DESPESAS PÚBLICAS E O NÍVEL DE DESENVOLVIMENTO HUMANO DOS ESTADOS BRASILEIROS: UMA ANÁLISE DO IDHM 2000 E 2010
}

Public expenditure and human development level of Brazilian states: an analysis of IDHM 2000 and 2010

Taíse Fatima Mattei

E-mail: taise_mattei_slo@hotmail.com Mestre em Gestão e Desenvolvimento Regional pela Universidade Estadual do Oeste do Paraná - Campus Francisco Beltrão; Doutoranda em Economia na Universidade Estadual de Maringá. Endereço para contato: Rua Tranquilo Baldim, 282, Santa Catarina, 89990-000, São Lourenço do Oeste, Santa Catarina, Brasil.

Fernanda Mendes Bezerra

E-mail: ferpompeia@gmail.com Doutora e Mestre em Economia pela Universidade Federal de Pernambuco; Professora no Programa de Mestrado em Gestão e Desenvolvimento Regional da Universidade Estadual do Oeste do Paraná - Campus Francisco Beltrão.

Gilmar Ribeiro de Mello

E-mail: gilmarribeirodemello@gmail.com Doutor e Mestre em Ciências Contábeis pela Universidade Federal de São Paulo; Professor Adjunto no Centro de Ciências Sociais Aplicadas e no Mestrado em Gestão e Desenvolvimento Regional da Universidade Estadual do Oeste do Paraná Campus Francisco Beltrão.

Artigo recebido em 19 de abril de 2016. Aceito em 15 de dezembro de 2016. 
Resumo

Uma das formas de um governo atuar na economia é na alocação dos gastos públicos. Os gastos públicos têm o objetivo de contribuir para o fornecimento de serviços públicos para a população, e também para a geração de investimentos na economia. Muitas vezes, questiona-se se esses gastos podem, de fato, contribuir para a melhoraria da vida das pessoas. Dessa forma, entender se as despesas públicas têm relação com o nível de desenvolvimento humano é importante para a tomada de decisão dos governantes e para melhorar a gestão dos gastos públicos, principalmente para direcionar em quais áreas devem ser gastos os recursos. Diante disso, o objetivo com este artigo foi verificar qual a contribuição das despesas públicas per capita por funções para o nível de desenvolvimento humano dos estados brasileiros. O método adotado é a regressão múltipla estimada pelo método de mínimos quadrados ordinários utilizando dados em painel. Os dados são provenientes do IBGE, PNUD e IPEA DATA. Os resultados sugerem que algumas despesas possuem contribuição positiva para o desenvolvimento dos estados. Analisando o modelo com todas as despesas na mesma regressão, saúde e educação apresentaram relação positiva para aumentar o IDHM. Analisando os modelos em regressões isoladas, as despesas com assistência e previdência, educação, saúde e segurança e transporte confirmaram impacto positivo sobre o nível de desenvolvimento dos estados. Destaca-se a importância das despesas com saúde e educação, as quais se apresentaram influenciáveis no desenvolvimento nas duas abordagens realizadas.

Palavras-chave: Despesas Públicas. Índice de Desenvolvimento Humano. Estados brasileiros.

\section{Abstract}

One of the ways for a government to act in the economy is in the allocation of public expenditures. Public expenditures aim to contribute to the provision of public services to the population, as well as to the generation of investments in the economy. It is often questioned whether such expenditures can actually contribute to the improvement of people's lives. Thus, understanding whether public expenditures arerelated to the level of human development is important for government decision-making, and to improve the management of public expenditures, mainly to target the areas in which resources should be spent. Therefore, the objective of this article is to verify the contribution of public expenditure per capita by functions to the level of human development of the Brazilian states. The method adopted is the multiple regression estimated by the ordinary least squares method using panel data. The data comes from IBGE, UNDP and IPEA DATA. The results suggest that some expenses have a positive contribution to the development of the states. Analyzing the model with all expenses in the same regression, health and education presented positive relation to increase the HDI. Analyzing the models in isolated regressions, assistance and pension, education, health, safety and transportation expenses confirmed a positive impact on the level of development of the states. It is important to highlight 
the importance of health and education expenditures, which were influential in the development of the two approaches.

Keywords: Public Expenditure. Human Development Index. Brazilian states.

\section{INTRODUÇÃO}

Os gastos públicos são a principal forma de atuação do governo, uma vez que, por meio deles,ele presta serviços públicos e investe na economia (RIANI, 2002). Os recursos que o governo utiliza para investir na melhoria de vida da população são limitados, por isso, devem ser utilizados de forma eficiente (LAZARIN;MELLO; BEZERRA, 2014). Muitas vezes fica evidente que o governo não investe seus recursos de forma adequada, e, por isso, não atinge o fim principal, atender às necessidades da população. Dessa forma, surgem questionamentos sobre a real contribuição dos gastos públicos para a melhoria de vida das pessoas.

Segundo Aragão et al. (2012), os recursos públicos podem contribuir para aumentar a qualidade de vida das pessoas, desenvolver novas tecnologias, melhorar a infraestrutura produtiva, atrair investimentos e aumentar o nível de emprego, entretanto, desde de que investidos de forma eficiente. Santos Filho, Dias Filho e Fernandes (2012) destacam a importância da decisão da alocação dos recursos públicos diante da escassez cada vez maior desses recursos.

Entender a contribuição das despesas públicas para o nível de desenvolvimento humano é importante para a tomada de decisão dos governantes, principalmente para direcionar em quais áreas devem ser gastos os recursos,no sentido de aumentar o nível de desenvolvimento. Diante disso, o problema da pesquisa é: qual a contribuição das despesas públicas per capita por funções para o nível de desenvolvimento humano dos estados brasileiros?

Portanto, o objetivo com o artigo foi verificar a contribuição das despesas públicas per capita por funções dos anos 1995 e 2005 para o nível de desenvolvimento humano dos estados brasileiros nos anos 2000 e 2010.

Este estudo se torna relevante à medida que pode verificar se os recursos que os estados estão utilizando estão dando retorno em longo prazo, contribuindo para a melhoria de vida da população e para o desenvolvimento humano, ou se estão sendo direcionados de forma equivocada. Esse conhecimento pode contribuir para uma melhor gestão dos gastos públicos e para melhorar o desenvolvimento econômico.

A escolha pelos estados brasileiros e pelo IDHM se justifica por existirem poucos estudos utilizando relação dos gastos públicos com a variável dependente de- 
senvolvimento. Um exemplo é o de Nova (2006), que relaciona os gastos públicos dos municípios cearenses com a variação do Índice de Desenvolvimento Humano para os anos 1991 e 2000. Existem alguns trabalhos que analisam a relação entre gastos públicos com crescimento econômico:o estudo de Bertussi e Ellery Junior (2010), que utiliza o gasto público em transporte dos estados brasileiros no período entre 1986 e 2007; e o estudo de Morais, Araujo e Monteiro (2012) para os municípios cearenses, de 2002 a 2009. Foram encontrados alguns trabalhos que analisam a eficiência dos gastos públicos em relação ao desenvolvimento humano, como o estudo de Anjos (2010), que analisa a eficiência dos gastos em saúde dos estados brasileiros. No entanto, não foram encontradosmuitos trabalhos que analisam o papel das despesas públicas para se atingir desenvolvimento parao Brasil como um todo.

O artigo conta com quatro seções, além desta introdução. Aprimeira fala sobre a economia do setor público, o desenvolvimento econômico, o IDH e IDHM e as despesas por funções. A segunda seção apresenta a metodologia, a terceira os resultados e discussões e, por fim, a última apresenta as considerações finais do trabalho.

\section{REVISÃO BIBLIOGRÁFICA}

Nesta seção serão abordados alguns aspectos sobre o papel do governo na economia e a utilização de seus recursos, bem como sobre o desenvolvimento humano e as despesas das diversas áreas de atuação do governo.

\subsection{A ECONOMIA DO SETOR PÚBLICO, O GOVERNO E OS GASTOS}

Grandes pensadores como Adam Smith, David Ricardo, Leon Walras, Alfred Marshall, John Stuart Mill e John Maynard Keynes formularam teorias de como deveria ser a intervenção do Estado na economia. Alguns deles, como Smith e Ricardo, defendiam a intervenção mínima do Estado, em que o mercado deveria atuar livremente. Walras e Marshall vieram a defender a intervenção do Estado para garantir a livre concorrência e Stuart Mill defendia que o governo deveria prover a sociedade de atividades que o setor privado não faria, como escolas, estradas e hospitais. Já Keynes, como viveu em uma época de grandes crises capitalistas, defendia a intervenção do Estado de forma inteligente para estabilizar e regular a economia. O Estado, para Keynes, deveria investir para aumentar o bem-estar da sociedade. Mesmo com tantos posicionamentos diferentes, a atuação do Estado se tornou cada vez mais presente a 
partir dos anos 1930 e ele começou a intervir cada vez mais na área fiscal e produtiva, além da área social, econômica e de regulamentação (RIANI, 2002).

Segundo Giambiagi e Além (2000), existem algumas razões pelas quais o governo precisa intervir procurando corrigir as falhas de mercado e garantir a produção ótima que satisfaça às necessidades da sociedade, como: quando existem bens públicos, que são bens indivisíveis eque não pode ser estabelecido preço via mercado, justificando então a necessidade de serem fornecidos pelo governo; quando existem monopólios naturais,que pode ser mais vantajoso apenas uma empresa fornecer esse bem, e o governo pode atuar fornecendo ou regulando para que não exista monopólio e cobrança de preço abusivo; quando existem externalidades positivas ou negativas, o governopode agir concedendo subsídios à geração de externalidadespositivas, cobrando multas e impostos para as externalidades negativas e regulamentando essas ações;quando existem mercados incompletos, em que um bem ou serviço não é ofertado por falta de recursos ou interesses, e, nesse caso, a intervenção do governo é importante para fornecer investimentos para o setor produtivo crescer;quando existem falhas de informação, em que o mercado por si só não fornece informações suficientes para a tomada de decisão, e a ação do governo se justifica na criação de leis para a transparência do mercado e para a eficiência nos fluxos de informações; e quando é para corrigir problemas como inflação e desemprego.

Depois dasrazões da intervenção do governo, é necessário entender quais são as suas funções básicas. Segundo Oliveira (2016), as três funções básicas são: alocação dos recursos, distribuição de renda e riqueza e estabilização econômica.Na função distributiva, o objetivo do governo é possibilitar a melhor distribuição de renda e riqueza entre os habitantes. Os meiospara isso são:a tributação, as transferências, os subsídiose também as legislações específicas. Dois exemplos de ações distributivas são impostos de renda e programas sociais. Na função de estabilização econômica, o objetivo principal é manter o nível de emprego e estabilizar o valor da moeda.

Segundo Giambiagi e Além (2000) e Riani (2002), na função alocativa o governo tem o objetivo de ofertar bens e serviços necessários que não são ofertados pelo setor privado, incluindo bens sociais e econômicos. São exemplos de ações alocativas: fornecimento de bens públicos puros, saúde, educação, transporte, energia elétrica, siderurgia, entre outros. Para que um Estado consiga desemprenhar todas as suas funções, ele utiliza uma ferramenta chamada gastos públicos. Os gastos públicos podem ser conceituados como o custo da quantidade e da qualidade dos serviços e bens ofertados. Consideram-se gastos públicos todos os gastos governamentais, ou 
seja, despesas das unidades que compõem a administração direta e indireta, mais as despesas do governo com as atividades econômicas produtivas (RIANI, 2002).

Araújo, Monteiro e Cavalcante (2010) apontam que existem vários fatores que afetam o nível dos gastos do governo, entre eles: a renda nacional, a capacidade do governo em obter receitas, os problemas sociais, as alterações no cenário político, o desenvolvimento tecnológico, os gastos em períodos anteriores, entre outros.

Os gastos públicos são classificados quanto à finalidade, natureza e execução do gasto. Referente à finalidade, os gastos são representados pelas funções do governo, programas e subprogramas, e têm por objetivo aumentar a eficiência e eficácia na programação dos gastos do governo. Quanto à natureza, são divididos em categorias: custeio, investimento, transferências e inversões financeiras. E, por fim, quanto à natureza da execução, podem ser para administração direta ou indireta (REZENDE, 1987).

Segundo Rezende, Slomski e Corrar (2005), o governo fornece serviços à sociedade com o objetivo de satisfazer às necessidades da população e aumentar o nível de bem-estarsocial,para isso, precisa arrecadar recursos financeiros. Giambiagi e Além (2000) enfatizam que a principal fonte de receita do setor público é a arrecadação de tributos. Para que a tributação se aproxime de um sistema ideal, todos os indivíduos devem pagar uma contribuição considerada justa. As pessoas com maior rendimentodevem pagar mais, o sistema deve ser simples para o entendimento e a administração do sistema ser eficiente.

O governo tem o papel de fornecer serviços à população e atingir o bem comum e, para isso, cobra impostos. Muitas vezes, sabe-seque o governo não investe seus recursos de forma adequada e não atinge o fim principal de atender às necessidades da população. A corrupção e a falta de responsabilidade acabam por tornar a administração ineficiente. Diante disso, precisa-se de governantes responsáveis com a população e cientes de suas funções, para que possam justificar sua existência fazendo aquilo que é de interesse de todos.

A população, na maioria das vezes, espera que os governantes invistam os recursos de forma adequada e promovam o desenvolvimento das suas regiões. Nesse sentido, serão abordados alguns aspectos sobre o desenvolvimento e suas conceituações.

\subsection{DESENVOLVIMENTO ECONÔMICO}

O Programa das Nações Unidas define desenvolvimento diferente do crescimento econômico, uma vez que não considera que o bem-estar de uma população seja apenas função da renda, mas também analisa as pessoas, suas oportunidades e capa- 
cidades. A renda é vista como um meio para atingir esse bem-estar, não um fim. Esse conceito também considera o avanço na qualidade de vida das pessoas, analisando as características sociais, culturais e políticas (PROGRAMA DAS NAÇÕES UNIDAS PARA O DESENVOLVIMENTO, 2015a). Muitas vezes, o processo de desenvolvimento econômico é encarado como socioeconômico, já que abrange a questão da melhoria social, nível de vida e bem-estar e tem como condição integrante o crescimento econômico (TEIXEIRA, 2005).

O Instituto de Pesquisa Econômica Aplicada (2014) e Oliveira (2016) constatam que, por muito tempo, o termo desenvolvimento era entendido como sinônimo de crescimento. Países eram considerados desenvolvidos porque tinham altas taxas de crescimento econômico. Com o tempo, a análise mais aprofundada dos países demostrou que, mesmo tendo altas taxas de crescimento, possuíam muitos problemas sociais e de distribuição de renda, evidenciando que crescer não necessariamente era desenvolver.

Nova (2006, p. 14) relata que:

O bem-estar da população não está relacionado apenas com o
nível médio da renda, já que uma renda extremamente concen-
trada pode significar que a grande maioria da população tem
um nível de renda muito baixo e, portanto, vive mal. É preciso
considerar a questão da desigualdade na distribuição da renda,
bem como outros indicadores de desenvolvimento social como
proporção da população que é alfabetizada, o grau médio de
instrução, longevidade, o acesso a serviços básicos de saúde e
saneamento.

Para Veiga (2001), o desenvolvimento pode ser entendido como a expansão das condições humanas de saúde, educação, comunicação, liberdade, entre outras, além de haver maiores possibilidades de escolha de recursos onde existe maior desenvolvimento econômico. Segundo o Programa das Nações Unidas Para o Desenvolvimento (2015a), o desenvolvimento pode ser conceituado também como a possibilidade de aumento das escolhas das pessoas, dando a possibilidade de serem aquilo que almejam ser.

O progresso de um país não pode ser medido apenas pelo dinheiro que as pessoas possuem.Saúde, educação, moradia, segurança, entre outros serviços de qualidade devem estar presentes na interpretação de desenvolvimento (SCARPIN; SLOMSKI, 2007). O desenvolvimento não deve ser pensado somente em termos econômicos propriamente ditos, mas deve incluir os aspectos sociais, pois a melhoria de vida da população é o que garante o seu verdadeiro desenvolvimento. 
Nesse sentido, destaca-se o papel do Estado na promoção do desenvolvimento. O Estado tem mecanismos e recursos, que se aplicados de maneira correta, podem contribuir para melhorar o desenvolvimento dos estados e o nível de vida das pessoas. Cabe agora verificar as medidas mais utilizadas para tentar medir o desenvolvimento humano.

\subsection{IDH E IDHM}

O Índice de Desenvolvimento Humano (IDH)foi criado por MahbubulHaq com a colaboração do economista indiano Amartya Sen, ganhador do Prêmio Nobel de Economia de 1998, e foi publicado pela primeira vez em 1990, com a pretensão de ser uma alternativa ao PIB per capita que leva em consideração apenas o aspecto econômico do desenvolvimento. O IDH é formado por três dimensões: saúde, educação e renda (PROGRAMA DAS NAÇÕES UNIDAS PARA O DESENVOLVIMENTO, 2015b).

Segundo Nova (2006, p. 12), “esse índice é importante porque associa indicadores de renda per capita, de educação e longevidade, o que sem dúvida lhe permite capturar melhor a satisfação do bem-estar percebido pelas pessoas”.

O PROGRAMA DAS NAÇÕES UNIDAS PARA O DESENVOLVIMENTO (2015b) aponta que “aos poucos, o IDH tornou-se referência mundial. É um índice-chave dos objetivos de desenvolvimento do milênio das Nações Unidas e, no Brasil, tem sido utilizado pelo governo federal e por administrações regionais através do Índice de Desenvolvimento Humano Municipal (IDH-M).”

O IDHM brasileiro também segue as três dimensões do IDH global, longevidade, educação e renda, e tem um diferencial por adequar a metodologia global ao contexto brasileiro, sendo mais utilizado por avaliar o desenvolvimento dos municípios brasileiros e por se adaptar à disponibilidade de indicadores nacionais. $\mathrm{O}$ índice varia de 0 a 1 e quanto mais próximo de 1 , maior o desenvolvimento humano (PROGRAMA DAS NAÇÕES UNIDAS PARA O DESENVOLVIMENTO, 2015c). Assim, segundo o Atlas Brasil2013 (2015) “o IDHM conta um pouco da história dos municípios, estados e regiões metropolitanas em três importantes dimensões do desenvolvimento humano durante duas décadas da história brasileira.”

Dessa forma, o IDH e o IDHM são índices que buscam analisar o desenvolvimento humano, de municípios, de estados e de países, abrangendo aspectos de qualidade de vida, educação e renda. Serão analisadas agora as despesas das diversas áreas de atuação do governo em busca da promoção do desenvolvimento dos municípios brasileiros. 


\subsection{DESPESAS POR FUNÇÕES}

As despesas por funções correspondem às despesas das diversas áreas de atuação do governo e retratam a aplicação dos recursos segundo essas funções. As despesas públicas por funções são definidas, segundo o IBGE (2006), como:

a) Administração e planejamento: despesas nas ações com objetivo administrativo e que auxiliam na execução de diversos programas do governo;

b) Agricultura: despesas nas atividades de elaborar e executar políticas de organização agrária, projetos de irrigação, fiscalização e defesa sanitária animal e vegetal, órgãos de cadastro de imóveis rurais e de cartografia, construção e manutenção de armazéns, de promoção e extensão rural;

c) Assistência e previdência: corresponde às despesas com amparo e proteção de pessoas e grupos com a finalidade de reduzir ou evitar desequilíbrios sociais e operação e suporte dos órgãos encarregados dos programas de benefícios a servidores ativos e inativos;

d) Educação e cultura: despesas voltadas à formação intelectual, moral, cívica e profissional do homem e inclui também as ações e políticas destinadas ao incentivo e à promoção de programas culturais e desportivos;

e) Energia e recursos minerais: despesas naelaboração e execução de políticas de eletrificação urbana e rural, geração e distribuição de energia não convencional (eólica, solar e termelétrica);

f) Segurança nacional e defesa pública: despesas dos órgãos encarregados do planejamento e demais atividades ligadas à segurança pública e às instituições do Poder Judiciário estadual e inclui também as ações desenvolvidas pelos órgãos encarregados da promoção da defesa nacional;

g) Habitação e urbanismo: despesas das ações destinadas a proporcionar melhores condições de vida às concentrações urbanas e propiciar moradia à população;

h) Indústria, comércio e serviços: despesas na elaboração de políticas de incentivo às indústrias, comércio, serviços e turismo; 
i) Legislativa: despesas na administração, operação e suporte dos órgãos legislativos e inclui todas as ações das Assembleias Legislativas e Câmaras Municipais;

j) Relações exteriores: despesas na administração, operação e suporte dos órgãos encarregados da política externa;

k) Saúde e saneamento: despesas nas ações de promoção, proteção, recuperação e reabilitação, desenvolvidas com o objetivo da melhoria do nível de saúde da população;

1) Trabalho: corresponde às despesas com a administração, operação e suporte dos órgãos encarregados das relações com a força de trabalho e dos interesses profissionais do trabalhador;

m) Transporte: refere-se às despesas de elaboração de políticas, controle, segurança, construção e manutenção de rodovias, ferrovias, eclusas e de terminais rodoviários, ferroviários, hidroviários e aéreos.

As aplicações dos recursos públicos nessas funções serão testadas neste artigo como possíveis indutoras de desenvolvimento dos estados brasileiros.

\section{METOdologia}

A pesquisa, quanto à abordagem, é quantitativa. O método de análise estatística é a regressão múltipla com dados em painel, baseado no modelo Mínimos Quadrados Ordinários (MQO). Para a realização do painel foi utilizado o software Stata 12 .

Os anos 2000 e 2010 foram escolhidos por serem os que possuem os dados de IDHM disponíveis. Os dados das despesas públicas para os anos 1995 e 2005 foram escolhidos porque, segundo Rocha e Giuberti (2007, p. 471), “essa defasagem é escolhida porque deve demorar algum tempo para que o gasto público afete o crescimento”, considerando aqui a mesma lógica para o desenvolvimento humano expresso pelo IDHM. Portanto, neste artigo, os dados referentes às despesas públicas foram coletados considerando uma defasagem de cinco anos em relação ao IDHM.

Inicialmente a proposta seria analisar as despesas per capita dos anos 1986, 1995 e 2005 com os IDHMs de 1991, 2000 e 2010, porém, pelo fato de os dados das despesas de 1986 se encontrarem em um período altamente inflacionário no Brasil, 
houve muita discrepância dos dados, acarretando a presença de heterocedasticidade no modelo. Assim, optou-se pela retirada dos dados de 1986 a fim de melhorar a especificação do modelo.

A amostra conta com os 26 estados brasileiros mais o Distrito Federal. Os dados de fonte secundária foram coletados do site do IBGE para as estimativas populacionais de 1995 e 2005, do IPEA DATA para as despesas públicas por funções de 1995 e 2005, e do PNUD parao IDHM 2000 e 2010. Os dados coletados referentes às despesas públicas nas diversas funções foram transformados em termos per capita, efetuando, portanto, a divisão de todas as despesas pela população obtida por meio do IBGE.

A variável dependente é o Índice de Desenvolvimento Humano Municipal (IDHM). As variáveis independentes são a população e as despesas públicas per capitapor funções: administração e planejamento, agricultura, assistência e previdência, educação e cultura, energia e recursos minerais, segurança nacional e defesa pública, habitação e urbanismo, indústria, comércio e serviços, legislativa, relações exteriores, saúde e saneamento, trabalho e transporte. A variável população é utilizada no modelo como variável de controle para as diferenças populacionais com base em Nova (2006).

O modelo será estimado de duas formas, conforme as Equações 1 e 2:

$$
\begin{aligned}
& I D H M=\alpha+\beta_{1} \operatorname{lnPop}_{i t}+\beta_{2} \ln A d m p c_{i t}+\beta_{3} \operatorname{lnAgripc}_{i t}+\beta_{4} \operatorname{lnAssistpc}_{i t}+ \\
& \beta_{5} \operatorname{lnEducp} c_{i t}+\beta_{6} \operatorname{lnEnergpc}_{i t}+\beta_{7} \operatorname{lnHabipc_{it}}+\beta_{8} \operatorname{lnIndpc_{it}}+\beta_{9} \ln \text { Legipc }_{i t}+ \\
& \beta_{10} \operatorname{lnRelapc}_{i t}+\beta_{11} \operatorname{lnSaúdepc}_{i t}+\beta_{12} \operatorname{lnSegpc}_{i t}+\beta_{13} \operatorname{lnTrabpc}_{i t}+\beta_{14} \operatorname{lnTranspc_{it}}+ \\
& \mu_{i t}
\end{aligned}
$$

$$
I D H M=\alpha+\beta_{1} \operatorname{lnPop}_{i t}+\beta_{2} \operatorname{lnDespesasfunçõespc~} i t+\mu_{i t}
$$

A primeira equação relacionará uma função com a população e com todas as despesas per capita conjuntamente, ou seja, com todas as despesas na mesma regressão. A segunda equaçãorelacionará uma função para cada despesa per capita separadamente, em regressões com dados em painel isoladas com a população, totalizando 13 regressões, em que despesasfunçõespc representa cada despesa per capita separadamente, e os subscritos iet representam no estado $i$ e no tempo $t$. A utilização de regressões com as variáveis independentes população e cada despesa per capita por função individualmente se justifica, conforme Nova (2006), pelo fato de poder existir elevada correlação entre as diversas despesas por funções, o que pode indicar presença de multicolinearidade. 
Após a formação do banco de dados será aplicada a técnica estatística de regressão para painel, e aplicados testes para a avaliação dos pressupostos. Todas as regressões serão elaboradas considerando os desvios robustos, que segundo Fávero et al. (2009), servem para inserir a matriz de White e detectar e corrigir situações de heterocedasticidade. O nível de significância considerado será de 5\%.

\subsection{REGRESSÃO COM DADOS EM PAINEL}

Os dados em painel são várias observações de corte transversal medidas em diferentes pontos no tempo, permitindo modelagens mais robustas que captam efeitos não vistos em apenas uma análise de corte transversal (FIGUEIREDO, 2011). Frees (2004) utiliza o termo dados longitudinais para chamar os dados em painel como um casamento de regressão e análise de séries temporais.

O modelo de dados em painel apresenta duas formas de modelagem: uma que analisa os efeitos fixos, e outra que analisa os efeitos aleatórios. Marques (2000, p.11) apresenta o modelo de efeitos fixos como aquele que "os coeficientes podem variar de indivíduo para indivíduo ou no tempo, ainda quepermaneçam como constantes fixas, logo, não aleatórias.” Ainda Marques (2000, p. 15)mostra que “o modelo de efeitos aleatórios pressupõe que o comportamento específico dos indivíduos eperíodos de tempo é desconhecido, não podendo ser observado, nem medido [...]”

Com a finalidade de escolha entre um modelo de efeitos fixos ou aleatórios, o teste de Hausman verifica a viabilidade do modelo de efeitos aleatórios a partir de análise de hipóteses (FIGUEIREDO, 2011). A hipótese nula de Hausman é que o modelo mais adequado seja o de efeitos aleatórios, e a hipótese alternativa é que o modelo de efeitos fixos seja o mais apropriado (FÁVERO et al., 2009).Segundo Torres-Reyna (2007), se a estatística p do teste for maior que 0,05 , não se rejeita a hipótese nula, e o modelo de efeitos aleatórios deve ser escolhido.No entanto, se o p for menor que 0,05, rejeita-se a hipótese nula e o modelo de efeitos fixos deve ser escolhido.

Feitas as observações metodológicas, parte-se para a apresentação, análise e discussão dos resultados.

\section{RESULTADOS E DISCUSSÕES}

Inicialmente, foram analisadas as regressões utilizando vários modelos de funções com o objetivo de encontrar o modelo que mais se adaptasse aos dados das 
variáveis dependentes e independentes. Entre as funções testadas (linear, logarítmica, potência e exponencial), a que apresentou o maior coeficiente de determinação ajustado $\left(\mathrm{R}^{2}\right)$ foi o modelo com função logarítmica. Para aplicar o modelo com função logarítmica, as variáveis independentes foram transformadas em logaritmo natural (ln).

Na análise de correlação e significância,as variáveis independentes expressas pelas despesas por funções per capita na assistência e previdência, educação, saúde, e segurança pública apresentaram correlação positiva acima de 0,50 e significância a 5\% com a variável dependente IDHM. A variável população e as despesas com agricultura, habitação e urbanismo, legislativa, trabalho e transporte também apresentaram correlação positiva e significativa com o IDHM, porém em nível menor. No entanto, algumas variáveis independentes expressas pelas despesas por funções per capita apresentaram elevada correlação entre si, o que pode causar multicolinearidade ao modelo se forem analisadas conjuntamente. Por exemplo, a despesa per capita com agricultura apresentou correlação elevada e significativa com administração; as despesas per capita com educação e cultura, energia, legislativa, saúde, trabalho e transporte apresentaram correlação elevada e significativa com administração e agricultura; a despesa per capita com trabalho apresentou elevada correlação e significativa com energia; a despesa per capita com segurança pública apresentou correlação com legislativa; e a despesa per capita com transporte apresentou correlação com saúde.

A primeira análise de regressão feita utiliza a variável dependente IDHM com a população e todas as despesas per capita por funçõesconjuntamente, conforme a Tabela 1:

Tabela 1 - Regressão com efeitos aleatórios robustos - modelo conjunto (continua)

\begin{tabular}{lcccc}
\hline \multicolumn{1}{c}{ Variáveis } & Coeficientes & Erro padrão robusto & t & P>|t| \\
\hline Constante & $-0,5318317$ & 0,137907 & $-3,86$ & 0,000 \\
Ln população & 0,0422969 & 0,008524 & 4,96 & 0,000 \\
Ln administração per capita & 0,0155011 & 0,006364 & 2,44 & 0,015 \\
Ln agricultura per capita & 0,0138819 & 0,010444 & 1,33 & 0,184 \\
Ln assistência e prev. per capita & 0,0248006 & 0,007922 & 3,13 & 0,002 \\
Ln educação per capita & 0,0393817 & 0,015354 & 2,56 & 0,010 \\
Ln energia per capita & 0,0003914 & 0,002624 & 0,15 & 0,881 \\
Ln habitação per capita & 0,0013351 & 0,003121 & 0,43 & 0,669 \\
Ln indústria per capita & $-0,0089783$ & 0,002709 & $-3,31$ & 0,001 \\
Ln legislativa per capita & 0,0199909 & 0,014780 & 1,35 & 0,176 \\
Ln relaç. ext. per capita & 0,0010738 & 0,001690 & 0,64 & 0,525 \\
\hline
\end{tabular}




\begin{tabular}{lrrrr} 
& & & & (conclusão) \\
\hline \multicolumn{1}{c}{ Variáveis } & Coeficientes & Erro padrão robusto & $\mathbf{t}$ & $\mathbf{P}>|\mathbf{t}|$ \\
\hline Ln saúde per capita & $-0,0090751$ & 0,009891 & $-0,92$ & 0,359 \\
Ln seg. púb. per capita & 0,0215989 & 0,011977 & 1,80 & 0,071 \\
Ln trabalho per capita & 0,0057084 & 0,003771 & 1,51 & 0,130 \\
Ln transporte per capita & 0,0030339 & 0,008311 & 0,37 & 0,715 \\
R-sq: within $=0,97$ & Prob> F $=0,0000$ & & F $=1193,67$ \\
\hline
\end{tabular}

Fonte: os autores.

Nota: Baseada nos resultados dos Stata 12.

Por meio do teste de Hausman, o modelo mais apropriado foi o de efeitos aleatórios em que prob>chi2 = 0,4588, não rejeitando a hipótese nula.

Para analisar a significância das variáveis no modelo de regressão, analisa-se a prob. de F e a prob. de t. Segundo Torres-Reyna (2007), prob. de F menor que 0,05 significa que pelos menos um coeficiente é diferente de 0 . Já a prob. de $|t|$ serve para avaliar cada coeficiente individualmente, se cada coeficiente é diferente de 0. A hipótese nula é que os coeficientes são iguais a 0 . Se o valor de $\mathrm{P}>|\mathrm{t}|$ for maior que 0,05 não se rejeita a hipótese nula e a variável não é significativa para o modelo.

Algumas variáveis independentes não se apresentaram estatisticamente significativas. Várias exclusões foram feitas até chegar a um modelo em que todas as variáveis independentes fossem significativas a 5\%, permanecendo o modelo apenas com a população e as despesas per capita com educação e saúde. O teste de Hausman identificou que o modelo mais adequado é o de efeitos fixos, conforme a Tabela 2.

Tabela 2 - Teste de Hausman- modelo conjunto, variáveis significativas

\begin{tabular}{|c|c|c|c|}
\hline \multirow{2}{*}{ Variáveis } & \multicolumn{2}{|c|}{ Coeficientes } & \multirow{2}{*}{ Diferença } \\
\hline & Fixo & Variável & \\
\hline Ln população & 0,2107 & 0,0443 & 0,1665 \\
\hline Ln educação per capita & 0,0631 & 0,0898 & $-0,0266$ \\
\hline Ln saúde per capita & 0,0177 & 0,0188 & $-0,0004$ \\
\hline Prob $>$ chi $2=0.0032$ & & & \\
\hline
\end{tabular}

Nota: Baseada nos resultados do Stata 12.

A regressão para efeitos fixos com as variáveis significativas conjuntamente segue na Tabela 3, juntamente com o teste de Wald para a heterocedasticidade: 
Tabela 3 - Regressão com efeitos fixos robustos - modelo conjunto

\begin{tabular}{lcccccr}
\hline \multicolumn{1}{c}{ Variáveis } & Coeficientes & $\begin{array}{c}\text { Erro padrão } \\
\text { robusto }\end{array}$ & $\mathbf{t}$ & $\mathbf{P}>|\mathbf{t}|$ & $\mathbf{9 5 \%}$ intervalo conf. \\
\hline Constante & $-2,9346600$ & 0,674760 & $-4,35$ & 0,000 & $-4,3216$ & 1,5476 \\
Ln população & 0,2107480 & 0,046111 & 4,57 & 0,000 & 0,1159 & 0,3055 \\
Ln educação per capita & 0,0631420 & 0,012840 & 4,92 & 0,000 & 0,0367 & 0,0895 \\
Ln saúde per capita & 0,0176960 & 0,008364 & 2,12 & 0,044 & 0,0005 & 0,0348 \\
\hline R-sq.: Within $=0,94$ & Prob> F =0,0000 & & & F = 163,83 & & \\
\hline Teste Wald: Prob>chi2 $=1,0000$ & & & & & & \\
\hline
\end{tabular}

Fonte: os autores.

Nota: Baseada nos resultados do Stata 12.

Por meio dos resultados apresentados na Tabela 3, pode-se verificar que o poder explicativo do modelo $\left(\mathrm{R}^{2}\right)$ é de ordem de $94 \%$ e se mostra significativo, uma vez que apresenta prob. de F menor que 0,05. As variáveis individualmente também são estatisticamente significativas, pois apresentam prob. $|\mathrm{t}|$ menor que 0,05 .

O teste de Wald é elaborado apenas para as regressões de efeitos fixos e serve para detectar a presença de heterocedasticidade. A hipótese nula é que os resíduos são homocedásticos. Se o valor de p for menor que 0,05, rejeita-se a hipótese nula e conclui-se que existe heterocedasticidade (MEHMOOD; MUSTAFA, 2014). Por meio do resultado do teste, não foi encontrada heterocedasticidade no modelo.

O teste de autocorrelação no Stata para dados em painel não pode ser efetuado. Esse teste é indicado para painéis com elevado número de anos na análise segundo Torres-Reyna (2007), o que não é o caso deste artigo que possui apenas dois períodos sendo analisados.

Como não foi possível encontrar um teste específico para a multicolinearidade dos dados em painel, o teste de multicolinearidade foi elaborado efetuando as regressões múltiplas não considerando o painel. O teste de multicolinearidade segue na Tabela 4:

Tabela 4 - Teste de multicolinearidade- modelo conjunto

\begin{tabular}{lccc}
\hline Variáveis & VIF & \multicolumn{2}{c}{ 1/VIF } \\
\hline Ln educação per capita & 4,06 & 0,24 \\
Ln saúde per capita & 3,75 & 0,26 \\
Ln população & 1,16 & 0,86 \\
Mean VIF & 2,99 & \\
\hline
\end{tabular}

Fonte: os autores.

Nota: Baseada nos resultados do Stata 12. 
Segundo Fávero et al. (2009), a interpretação indica que VIF acima de 10 apresenta multicolinearidade problemática e 1/VIF abaixo de 0,10 também apresenta multicolinearidade problemática. Pode-se perceber que a multicolinearidade não é problemática no modelo.

A normalidade foi verificada usando o teste de Shapiro-Wilk, cuja prob. z deve ser maior que 0,05 para que a hipótese nula de normalidade não seja rejeitada (CORRAR; PAULO; DIAS FILHO, 2007). O teste de normalidade dos resíduos segue na Tabela 5 , em que se pode afirmar que o erro segue uma distribuição normal, não rejeitando a hipótese nula:

Tabela 5 - Teste de normalidade -modelo conjunto

\begin{tabular}{cr}
\hline Variável & Shapiro-Wilk teste de normalidade / prob z \\
\hline $\mathrm{u}$ & 0,782 \\
\hline Fonte: os autores.
\end{tabular}

Nota: Baseada nos resultados do Stata 12.

Depois de verificados os pressupostos, é possível destacar que a população e as despesas com educação e saúde per capita apresentaram relação positiva com o IDHM, isto é, quanto maiores as despesas estaduais nessas áreas, maior o IDHM. Essas duas categorias de despesas contribuem para elevar o nível de desenvolvimento dos estados. Interpretando os resultados,para cada 1\% de aumento nas despesas per capita destinados à educação, obtém-se 0,063 pontos de acréscimo no nível de IDHM, e se o mesmo percentual de aumento de gastos for destinado à saúde, acrescenta-se 0,017 pontos no nível do IDHM. Percebe-se o papel importante da educação e da saúde para aumentar o nível de bem-estar das pessoas, no entanto, esses resultados não surpreendem, já que as despesas com saúde e educação são obrigatórias para os governos.

Santos Filho, Dias Filho e Fernandes (2012) realizaram um trabalho relacionando as despesas por função dos municípios baianos com o IDHM para o ano 2000. Seus resultados revelaram, em um modelo conjunto, que despesas com planejamento, indústria e comércio, educação e cultura, habitação e urbanismo e judiciário contribuíam para elevar o desenvolvimento dos municípios baianos. Da mesma forma que o trabalho de Santos Filho, Dias Filho e Fernandes (2012), neste artigo também se encontrou relação positiva da despesa com educação para o desenvolvimento, no entanto, encontrou-se relação positiva também para as despesas com saúde, mas não para as demais despesas.

Os resultados encontrados neste artigo estão em conformidade, em alguns aspectos, com o estudo de Oliveira (2016). Ele encontrou, em um modelo analisando 
as despesas conjuntamente, contribuição positiva das despesas com agricultura, educação e cultura, saúde e saneamento e transporte para o desenvolvimento humano dos municípios brasileiros no ano 2000. Oliveira (2016) analisou também o ano 2010, e encontrou que as seguintes despesas contribuíam positivamente para o desenvolvimento dos municípios brasileiros: agricultura, habitação e urbanismo e transporte. No entanto, em 2010, encontrou contribuição negativa das despesas com educação e cultura bem como com assistência e previdência para o desenvolvimento dos municípios, e não encontrou contribuição das despesas com saúde para o IDHM em 2010, o que difere deste artigo.

A segunda análise de regressão feita utiliza a variável dependente IDHM com as despesas per capita por funções separadamente, em regressões isoladas com a população. A Tabela 6 mostra as 13 regressões com os coeficientes, com R² (R-sq) e com o teste de Hausman para cada regressão.

Por meio dos resultados, pode-se verificar que o poder explicativo $\left(\mathrm{R}^{2}\right)$ de todas as regressões se encontra acima de $79 \%$. Todos os modelos se mostram significativos analisando a prob>F, no entanto, apenas as despesas com agricultura, assistência e previdência, educação, legislativa, saúde e segurança e transporte apresentaram significância a 5\% quando analisados os parâmetros separadamente.

O teste de Hausman apontou que, com exceção das regressões com as despesas de agricultura e legislativa, todas as outras foram rodadas para efeitos fixos. 
Taíse Fatima Mattei, Fernanda Mendes Bezerra, Gilmar Ribeiro de Mello

Tabela 6 - Regressõesrobustas- modelos com despesas separadamente

\begin{tabular}{|c|c|c|c|c|c|c|c|c|c|c|c|c|c|}
\hline \multirow{2}{*}{$\begin{array}{c}\text { Variá- } \\
\text { veis }\end{array}$} & \multicolumn{13}{|c|}{ Regressões utilizando despesas per capita separadamente -variável dependente IDHM } \\
\hline & 1 & 2 & 3 & 4 & 5 & 6 & 7 & 8 & 9 & 10 & 11 & 12 & 13 \\
\hline $\begin{array}{l}\text { Cons- } \\
\text { tante }\end{array}$ & $-8,42 *$ & $-0,38 *$ & $-5,40^{*}$ & $-3,40 *$ & $-8,33 *$ & $-7,55^{*}$ & $-8,17 *$ & $-0,82 *$ & $-8,33 *$ & $-3,68 *$ & $-4,37 *$ & $-7,85 *$ & $-6,84 *$ \\
\hline $\begin{array}{l}\text { Ln } \\
\text { popu- } \\
\text { lação }\end{array}$ & $0,59 *$ & $0,05^{*}$ & $0,38 *$ & $0,24 *$ & $0,59 *$ & $0,54 *$ & $0,58 *$ & $0,07^{*}$ & $0,59 *$ & $0,27 *$ & $0,32 *$ & $0,56 *$ & $0,49 *$ \\
\hline $\begin{array}{l}\text { Ln } \\
\text { adm. }\end{array}$ & 0,004 & & & & & & & & & & & & \\
\hline Ln agric. & & $0,089 *$ & & & & & & & & & & & \\
\hline Ln assist. & prev. & & $0,047^{*}$ & & & & & & & & & & \\
\hline Ln educa & ção & & & $0,086 *$ & & & & & & & & & \\
\hline Ln energ & & & & & $-0,008$ & & & & & & & & \\
\hline Ln habita & ção urb. & & & & & 0,010 & & & & & & & \\
\hline Ln indúst & & & & & & & 0,005 & & & & & & \\
\hline Ln legisl & tiva & & & & & & & $0,111^{*}$ & & & & & \\
\hline Ln relaçõ & es ext. & & & & & & & & $-0,004$ & & & & \\
\hline Ln saúde & & & & & & & & & & $0,047^{*}$ & & & \\
\hline Ln segur & inça & & & & & & & & & & $0,044^{*}$ & & \\
\hline Ln trabal & & & & & & & & & & & & 0,005 & \\
\hline Ln transp & orte & & & & & & & & & & & & $0,022^{*}$ \\
\hline R-sq: & 0,790 & 0,820 & 0,910 & 0,940 & 0,810 & 0,810 & 0,800 & 0,910 & 0,800 & 0,910 & 0,870 & 0,800 & 0,830 \\
\hline $\begin{array}{l}\text { F-esta- } \\
\text { tistic }\end{array}$ & 33,07 & 270,67 & 117,72 & 191,72 & 41,54 & 40,45 & 32,61 & 365,46 & 187,52 & 137,92 & 53,48 & 33,88 & 41,86 \\
\hline $\begin{array}{l}\text { Pro- } \\
b>F\end{array}$ & 0,000 & 0,000 & 0,000 & 0,000 & 0,000 & 0,000 & 0,000 & 0,000 & 0,000 & 0,000 & 0,000 & 0,000 & 0,000 \\
\hline $\begin{array}{l}\text { Haus- } \\
\text { man }\end{array}$ & 0,000 & 0,064 & 0,000 & 0,002 & 0,000 & 0,000 & 0,000 & 0,144 & 0,000 & 0,002 & 0,004 & 0,000 & 0,000 \\
\hline
\end{tabular}

Fonte: os autores.

Nota:Baseada nos resultados do Stata 12.

* significância ao nível de 5\%.

Em relação aos pressupostos, a Tabela 7 apresenta os resultados dos testesde Wald para a heterocedasticidade das regressões com efeitos fixos, de Shapiro-Wilk para a normalidade, e de multicolinearidade pelo VIF e 1/VIF, rodado sem considerar painel. 
Tabela 7 - Teste dos pressupostos

\begin{tabular}{lccccccccccccc}
\hline $\begin{array}{l}\text { Variá- } \\
\text { veis }\end{array}$ & adm. & agric. & $\begin{array}{l}\text { assist. } \\
\text { prev. }\end{array}$ & educ. & energ. & $\begin{array}{l}\text { hab. } \\
\text { urb. }\end{array}$ & ind. & $\begin{array}{l}\text { le- } \\
\text { gisl. }\end{array}$ & $\begin{array}{l}\text { rel. } \\
\text { ext. }\end{array}$ & saúde & segur. & trab. & transp. \\
\hline Wald & 1,00 & - & 1,00 & 1,00 & 1,00 & 1,00 & 1,00 & - & 1,00 & 1,00 & 1,00 & 1,00 & 1,00 \\
$\begin{array}{l}\text { Sha- } \\
\text { piro- }\end{array}$ & 0,62 & 0,01 & 0,42 & 0,91 & 0,58 & 0,62 & 0,62 & 0,008 & 0,62 & 0,54 & 0,58 & 0,61 & 0,71 \\
-Wilk & & & & & & & & & & & & & \\
VIF & 1,59 & 1,19 & 1,09 & 1,13 & 1,08 & 1,02 & 1,00 & 1,58 & 1,04 & 1,05 & 1,00 & 1,00 & 1,07 \\
$1 /$ VIF & 0,62 & 0,83 & 0,91 & 0,88 & 0,92 & 0,97 & 0,99 & 0,63 & 0,96 & 0,95 & 0,99 & 0,99 & 0,93 \\
\hline
\end{tabular}

Nota: Baseada nos resultados do Stata 12.

Todas as modelagens para efeitos fixos não apresentaram heterocedasticidade. O teste de normalidade dos resíduos de Shapiro-Wilk revelou que apenas as regressões dos modelos com a função agricultura e legislativa per capita não atenderam a esse pressuposto. A multicolinearidade não é problemática entre as despesas e a população de cada regressão.

Depois da análise dos pressupostos, é possível a interpretaçãodos resultados das regressões. As despesas que foram significativas, ou seja, que passaram em todos os testes dos pressupostos, e que contribuem para elevar o nível de desenvolvimento dos estados foram: assistência e previdência, educação, saúde e segurança e transporte. Dessas despesas, todas apresentaram relação positiva com o IDHM, isto é, aumentando as despesas, o nível de desenvolvimento humano aumenta.

Entre as despesas significativas, as que apresentaram os valores maiores dos coeficientes foram: despesas com educação, saúde e assistência e previdência. Para cada $1 \%$ de aumento nas despesas per capita destinados à educação, acrescenta-se 0,086 pontos no nível do IDHM; a cada 1\% de aumento nas despesas per capita destinados à saúde e assistência e previdência, acrescenta-se 0,047 pontos no nível do IDHM.

Os resultados encontrados neste artigo, na regressão das despesas de forma separada, estão em conformidade com os resultados encontrados por Nova (2006), que buscou analisar o impacto dos gastos públicos para o desenvolvimento dos municípios cearenses em 1991 e 2000. Esse autor encontrou impacto positivo dos gastos com educação e segurança para o desenvolvimento dos municípios cearenses, no entanto, não encontrou relação das despesas com saúde para o desenvolvimento, o que diverge dos resultados deste artigo.

Além disso, os resultados deste artigo também estão em conformidade com os encontrados por Anjos (2010), que estudou a relação entre investimentos em saúde 
e o desenvolvimento dos estados brasileiros e encontrou que os estados brasileiros têm sido eficientes no investimento em saúde promovendo melhoria de vida para a população.

Prasetyo e Zuhdi (2013) fizeram um estudo para analisar a eficiência dos gastos públicos em saúde e educação para o desenvolvimento em 81 países durante 2006 e 2010. Encontraram alguns países que são eficientes no uso dessas despesas para o desenvolvimento, como: Armênia, Austrália, Bangladesh, Chile,Geórgia, Japão, República da Coreia, Madagascar, Níger, Noruega, Filipinas, Serra Leoa, Singapura e Zâmbia. No mesmo sentido, Poker Junior, Nunes e Nunes (2013) realizaram um estudo para avaliar a efetividade e eficiência dos gastos públicos exclusivamente da educação nos municípios brasileiros em 2000 e 2010 e encontraram uma contribuição positiva das despesas públicas em educação para o desenvolvimento humano. Os estudos de Prasetyo e Zuhdi (2013) e Poker Junior, Nunes e Nunes (2013) estão em conformidade com o que foi encontrado neste artigo, que gastos com educação e saúde apresentaram relação positiva com o IDHM, além de outras despesas como assistência e previdência e segurança e transporte.

Os resultados deste artigo sugerem aos gestores públicos que investimentos em educação, saúde, segurança, transporte e assistência e previdência contribuem significativamente para elevar o nível de vida das pessoas, por isso, os recursos devem ser direcionados de forma efetiva e abundante para essas áreas.

Em conformidade com o que é defendido por Aragão et al. (2012), neste artigo mostrou que os recursos públicos geridos pelo governo podem contribuir para aumentar a qualidade de vida das pessoas, evidenciando em quais áreas devem ser direcionados os recursos quando se objetiva melhorar o desenvolvimento humano dos estados brasileiros.

\section{CONCLUSÃO}

O objetivo com este artigo foi verificar qual a contribuição das despesas públicas per capita por funções para o nível de desenvolvimento humano dos estados. Dessa forma, observou-se que algumas despesas foram importantes e possuíram relação positiva para elevar o nível de desenvolvimento humano dos estados brasileiros. Analisando as despesas conjuntamente, apenas saúde e educação se apresentaram significativas para aumentar o nível de desenvolvimento dos estados. Analisando as despesas individualmente em regressões isoladas com a população, as despesas com assistência e previdência, educação, saúde e segurança e transporte apresentaram-se significativas e passaram em todos os testes dos pressupostos, sendo úteis na eleva- 
çãodo nível de desenvolvimentos dos estados brasileiros. Em ambos os modelos, a relação encontrada foi positiva, ou seja, aumentando as despesas nas funções, aumenta-se o nível de desenvolvimento humano.

Destaca-se a importância da saúde e da educação, que se apresentaram significativas nas duas abordagens realizadas, o que pode indicar aos gestores públicos o direcionamento dos gastos estaduais principalmente para essas áreas. No entanto, esses resultados não foram surpreendentes, já que esses gastos são considerados obrigatórios para os estados. As demais despesas com assistência e previdência e segurança e transporte também se apresentaram significativas quando analisadas de forma isolada, portanto, também contribuem para elevar o nível de vida e bem-estar das pessoas.

Como o IDHM é composto por indicadores de saúde, educação e renda, também não éinusitado que as despesas com saúde e educação sejam significativas para explicar o nível de desenvolvimento, indicando que essas áreas contribuem de forma relevante para elevar o nível de desenvolvimento das pessoas e, por isso, devem ser direcionados cada vez mais recursos para elas. Dessa forma, percebe-se o papel importante do governo para promover melhoria no desenvolvimento de vida das pessoas e para direcionar os recursos de forma adequada por meio da execução de suas funções.

Algumas limitações foram encontradas na pesquisa, pode-se citar principalmente a falta de dados para construir uma série temporal maior, o que prejudicou também a elaboração dos testes de autocorrelação dos resíduos no Stata12. No entanto, neste trabalho não se pretende esgotar a discussão sobre essa temática, uma vez que, a partir deste, pode-se expandir a discussão analisando alguns municípios ou regiões específicas.

\section{REFERÊNCIAS}

ANJOS, R. M. dos. Relação entre investimento em saúde e desenvolvimento dos estados brasileiros. Dissertação (Mestrado em Administração de Organizações)Universidade de São Paulo, Ribeirão Preto, São Paulo, 2010. Disponível em: $<$ http:// www.teses.usp.br/teses/disponiveis/96/96132/tde-13122010-115745/en.php>. Acesso em: 29 mar. 2015.

ARAGÃO, C. H. S. et al. Impacto Das Despesas Públicas Por Função No Crescimento Econômico Brasileiro. Observatorio de La EconomíaLatino americana, n. 171, 2012. Disponível em: <http://www.eumed.net/cursecon/ecolat/br/12/asmm. pdf $>$. Acesso em: 14 nov. 2016. 
ARAÚJO, J. A. de; MONTEIRO, V. B.; CAVALCANTE, C. A. Influência dos gastos públicos no crescimento econômico dos Municípios do Ceará. In: ENCONTRO - ECONOMIA DO CEARÁ EM DEBATE, 6., 2010, Ceará. Anais eletrônicos... Ceará, 2010. Disponível em: <http://www.ipece.ce.gov.br/economia-do-ceara-emdebate/vi-encontro/trabalhos/Influencia_dos_gastos_publicos_no_crescimento_economico.pdf> . Acesso em: 25 abr. 2015.

ATLAS BRASIL. Atlas do Desenvolvimento Humano no Brasil- 2013.2015. Disponível em:<http://www.atlasbrasil.org.br/2013/pt/o_atlas/idhm/>. Acesso em: 03 ago. 2015.

BERTUSSI, G. L.; ELLERY JUNIOR, R. Gastos públicos com infraestrutura de transporte e crescimento econômico: uma análise para os estados brasileiros. Tese (Doutorado em Economia)-Universidade de Brasília, Brasília, DF, 2010. Disponível em: <http://repositorio.unb.br/handle/10482/8518>. Acesso em: 21 abr. 2015.

CORRAR, L.; PAULO, E.; DIAS FILHO, J. M. Análise Multivariada para os cursos de Administração, Ciências Contábeis e Economia. São Paulo: Atlas, 2007.

FÁVERO, L. P. et al. Análise de dados: modelagem multivariada para tomada de decisões. São Paulo: Elsevier, 2009.

FIGUEIREDO, C. de O. Análise da dependência espacial no contexto de dados em painel: o caso espaço-temporal. 2011. Dissertação (Mestrado em Estatística)Universidade de Brasília, Brasília, DF, 2011. Disponível em: <http://repositorio.unb. br/handle/10482/8639>. Acesso em: 27 abr. 2015.

FREES, E. Longitudinal and panel data: Analysis and Applications for the Social Sciences. Cambridge: Cambridge University Press, 2004. Disponível em: <http:// instruction.bus.wisc.edu/jfrees/jfreesbooks/Longitudinal\%20and\%20Panel\%20Data/ Book/Chapters/FreesFinal.pdf>.Acesso em: 27 abr. 2015.

GIAMBIAGI, F.; ALÉM, A. C. Finanças públicas: teoria e prática no Brasil.2. ed.rev. e atual.Rio de Janeiro: Elsevier, 2000.

IBGE. Despesas Públicas por Funções 1999-2002. Coordenação de Contas Nacionais. Rio de Janeiro,2006. Disponível em: <http://www.ibge.gov.br/home/estatistica/ economia/despesasfuncoes/despesasfuncoes2002.pdf>. Acesso em: 19 maio 2015. 
INSTITUTO DE PESQUISA ECONÔMICA APLICADA. Presente e futuro do desenvolvimento brasileiro. Brasília, DF: IPEA, 2014. 643p. Disponível em: $<$ http://www.ipea.gov.br/portal/images/stories/PDFs/livros/livros/150605_livro_presente_futuro.pdf $>$. Acesso em: 14 nov. 2016.

LAZARIN, M. de F.; MELLO, G. R. de; BEZERRA, F. M. A relação entre a dívida pública e o desenvolvimento socioeconômico dos municípios paranaenses: evidências para o período de 2002 a 2010. RACE-Revista de Administração, Contabilidade e Economia, Santa Catarina, v. 13, n. 2, p. 719-736, 2014. Disponível em: <http://editora.unoesc.edu.br/index.php/race/article/view/4207>. Acesso em: 15 abr. 2015.

MARQUES, L. D. Modelos dinâmicos com dados em painel: revisão de literatura. Porto, Portugal: Faculdade de Economia do Porto, 2000. Disponível em: <http:// wps.fep.up.pt/wps/wp100.pdf>. Acesso em: 27 abr. 2015.

MEHMOOD, B.; MUSTAFA, H. Empirical Inspection of Broadband-Growth Nexus: AFixed Effects with Driscoll and Kraay Standard Errors Approach. Pakistan Journal of Commerce and Social Sciences, Pakistan, v. 8, i.1, p.1-10, 2014. Disponível em: <http://www.jespk.net/publications/156.pdf>. Acesso em: 10 jul. 2015.

MORAIS, G. A. de S.; ARAUJO, J. A. de; MONTEIRO, V. B. Gastos públicos e crescimento econômico: evidências da economia cearense. In: ENCONTRO DO CEARÁ EM DEBATE, 8., 2012, Fortaleza. Anais eletrônicos... Fortaleza: IPECE, 2012. Disponível em: <http://www.repositorio.ufc.br/ri/handle/riufc/5429>. Acesso em: 02 jun. 2015.

NOVA, M. J. da. O impacto dos gastos públicos no Índice de Desenvolvimento Humano: o caso dos municípios do Ceará. Dissertação (Mestrado em Economia de Empresas)-Universidade Federal do Ceará, 2006. Disponível em: <http://www.repositorio.ufc.br/ri/handle/riufc/5589>. Acesso em: 15 abr. 2015.

OLIVEIRA, L. S. D. de. As despesas públicas municipais como determinantes no desenvolvimento humano. 2016. 103 p. Dissertação (Mestrado em Ciências Contábeis)-Universidade de Brasília, Universidade Federal da Paraíba e Universidade Federaldo Rio Grande do Norte, Natal, 2016. Disponível em: <http://repositorio.unb. br/handle/10482/20890>. Acesso em: 14 nov. 2016.

POKER JUNIOR, J. H.; NUNES, R. da C.; NUNES, S. P. Uma avaliação de efetividade e eficiência do gasto em educação em municípios brasileiros. Caderno de Finanças Públicas, Brasília, DF, n. 13, p. 263-287, dez. 2013. Disponível em: <http:// compromissocampinas.org.br/wp-content/uploads/2014/09/Uma_avaliacao_de_efetividade_e_eficiencia_do_gasto_em_educacao_.pdf>.Acesso em: 23 nov. 2016. 
PRASETYO, A. D.; ZUHDI, U. The Government Expenditure Efficiency towards the Human Development. Procedia Economics and Finance, Holanda, v. 5, p. 615-622, 2013. Disponível em: <http://www.sciencedirect.com/science/article/pii/ S2212567113000725>. Acesso em: 23 nov. 2016.

PROGRAMA DAS NAÇÕES UNIDAS PARA O DESENVOLVIMENTO. O que é Desenvolvimento humano? 2015a. Disponível em: <phttp://www.pnud.org.br/IDH/ DesenvolvimentoHumano.aspx?indiceAccordion=0\&li=li_DH>. Acesso em: 27 abr. 2015.

PROGRAMA DAS NAÇÕES UNIDAS PARA O DESENVOLVIMENTO. O que é o IDH? 2015b. Disponível em: <http://www.pnud.org.br/IDH/IDH.aspx?indiceAccordion=0\&li=li_IDH $>$. Acesso em: 18 maio 2015.

PROGRAMA DAS NAÇÕES UNIDAS PARA O DESENVOLVIMENTO. O que é o IDHM? 2015c. Disponível em: <http://www.pnud.org.br/IDH/IDHM.aspx?indiceAccordion=0\&li=li_IDHM $>$. Acesso em: 19 maio 2015.

REZENDE, A. J.; SLOMSKI, V.; CORRAR, L. J. A gestão pública municipal e a eficiência dos gastos públicos: uma investigação empírica entre as políticas públicas e o índice de desenvolvimento humano (IDH) dos municípios do Estado de São Paulo. Revista Universo Contábil, Santa Catarina, v. 1, n. 1, p. 24-40, 2005. Disponível em:<http://gorila.furb.br/ojs/index.php/universocontabil/article/view/75>. Acesso em: 15 abr. 2015.

REZENDE, F. A. Finanças Públicas. São Paulo: Atlas, 1987.

RIANI, F. Economia do setor público. 4. ed. São Paulo: Atlas, 2002.

ROCHA, F.; GIUBERTI, A. C. Composição do gasto público e crescimento econômico: uma avaliação macroeconômica da qualidade dos gastos dos Estados brasileiros. Economia Aplicada, São Paulo, v. 11, n. 4, p. 463-485, 2007. Disponível em: <http://www.scielo.br/scielo.php?pid=S1413-80502007000400001\&scri pt=sci_arttext\&tlng=es>. Acesso em: 06 jun. 2015.

SANTOS FILHO, M. R. dos; DIAS FILHO, J. M.; FERNANDES, G. B. Avaliação da capacidade de predição do Índice de Desenvolvimento Humano dos Municípios (IDH-M) a partir das demonstrações contábeis e legais. Revista Ciências Administrativas, Fortaleza, v. 18, n. 1, p. 83-109, jan./jun. 2012. Disponível em: <http://ojs.unifor.br/index.php/rca/article/view/3319>. Acesso em: 22 nov. 2016. 
SCARPIN, J. E.; SLOMSKI, V. Estudo dos fatores condicionantes do índice de desenvolvimento humano nos municípios do Estado do Paraná: instrumento de controladoria para a tomada de decisões na gestão governamental. Revista de Administração Pública, Rio de Janeiro, v. 5, n. 41, p. 909-933, 2007.Disponível em: <http:// www.scielo.br/pdf/rap/v41n5/a06v41n5.pdf>. Acesso em: 15 abr. 2015.

TEIXEIRA, N. G. Desenvolvimento econômico: notas sobre seu financiamento. Revista Desenbahia, Bahia, p. 7-23, 2005. Disponível em: <http://www.desenbahia. ba.gov.br/uploads/2408201114590937Revista2_mar2005.pdf\#page=7>.Acessoem: 15 abr. 2015.

TORRES-REYNA, O. Panel Data analysis fixed and random effects using Stata 10 (v. 4,2). Data and Statistical Service, Princeton: Princeton University, 2007. Disponível em: <http://www.princeton.edu/ otorres/Panel101.pdf>. Acesso em: 09 jul. 2015.

VEIGA, J. E. da. O Brasil rural ainda não encontrou seu eixo de desenvolvimento. Estudos Avançados, São Paulo, v. 43, n. 15, p. 101-119, 2001. Disponível em: $<$ http://www.scielo.br/scielo.php?pid=S0103-40142001000300010\&script=sci_arttext>.Acesso em: 18 abr. 2015.

\section{Como citar este artigo:}

\section{ABNT}

MATTEI, Taíse Fatima; BEZERRA, Fernanda Mendes; MELLO, Gilmar Ribeiro de. Despesas Públicas e o Nível de Desenvolvimento Humano dos Estados Brasileiros: uma análise do IDHM 2000 e 2010. RACE, Revista de Administração, Contabilidade e Economia, Joaçaba: Ed. Unoesc, v. 17, n. 1, p. 29-54, jan./abr. 2018. Disponível em: <http://editora.unoesc.edu.br/index.php/race> . Acesso em: dia/mês/ano.

APA

Mattei, T. F., BEZERRA, F. M. , \& Mello, G. R. de.(2018). Despesas Públicas e o Nível de Desenvolvimento Humano dos Estados Brasileiros: uma análise do IDHM 2000 e 2010. RACE, Revista de Administração, Contabilidade e Economia, 17(1), 29-54. Recuperado em dia/mês/ano, de http://editora.unoesc.edu.br/index.php/race 
